\title{
Investigating the Use of the Flipped Classroom Method in an EFL Vocabulary Course
}

\author{
Sarah S. Alnuhayt \\ Almuzahmiah Faculty of Education, Shaqra University, Riyadh, Kingdome of Saudi Arabia
}

\begin{abstract}
This study investigated the efficacy of using the flipped classroom method in EFL vocabulary classes. The participants consisted of 45 freshmenstudents enrolled in the researcher's ENG.120 Building vocabulary course in the English program of Al-Mezahemiah Faculty of Education; Shaqra University. The control group was taught traditionally by lecture- style learning while the experimental group was taught using the flipped classroom method. Data collection instruments included pre-post test and a questionnaire. Findings of the test indicated that the experimental group outperformed the control group in the post- test. Findings of the questionnaire indicated that students in the experimental group had positive attitudes regarding using the flipped classroom method in the EFL vocabulary class.
\end{abstract}

Index Terms - flipped classroom method, students' perceptions, vocabulary teaching techniques

\section{OVERVIEW}

The concept "flipped classroom" has been widely investigated recently. The flipped classroom is a method of teaching in which "what used to be classwork (the lecture) is done at home via teacher-created videos and what used to be homework (assigned problems) is now done in class" (Overmyer, 2014, p.1). They record their lectures by using video recordings (Hamdan, McKnight, McKnight, \& Arfstrom, 2013).

In the flipped classroom, the whole classroom structure is flipped and that is why it is called the flipped classroom (Overmyer, 2014). That is, the homework is done at the classroom and the lecture is delivered to students before class time (Baranovic, 2013). The main goal of flipping the classroom is to increase the face-to-face time between teachers and students (Gross, 2014) and devote class time for discussing topics, answering questions and practicing exercises (Mehring, 2015).

The flipped classroom method consists of video lectures that students watch before attending classes where they participate in activities or the teachers answer their questions. This is the opposite of the traditional teaching approach in which students listen to their teachers during classes but have activities with interactions and collaboration outside of classes. The flipped classroom is pedagogically convincing because it supports the principles of personalizeddifferentiated learning, student-centered instruction, and constructivism.

The fundamental principle of the flipped classroom model is to have more attention toward students and their learning without wasting class time needed to cover new content (Lage et al., 2000). The benefits of the flipped classroom include providing time and opportunities for better participation in class and to focus on higher-order thinking skills and difficult content. Therefore, the flipped classroom model enhances students' engagement, motivation, and improves academic performance (Tucker, 2012).

Probably, the greatest advantage of the flipped classroom is increasing the face-to-face time spent with both teachers and peers. Goodwin and Millera argue that the flipped classroom spares more time for the feedback of the teacher as well as better student-teacher interaction (2013). The flipped classroom is also praised for the meaningful discussions it can spur after a video lecture the night before. Students may enjoy the classroom environment as they end up leading the discussion and the learning.

However, the flipped classroom teaching strategy is not without limitations and criticism. Some scholars such as Lents \&Cifuentes (2009) and Strayer (2012) list their reasons for not using this new strategy. The question naturally arises: Is the flipped classroom vocabulary teaching strategy more effective compared with the traditional vocabulary teaching models? If so, are there any problems to be settled to improve this new teaching strategy? Bearing these questions in mind, the authors of the paper designed the following research to find out the effects of vocabulary teaching in flipped classroom.

Furthermore, some parents and teachers tend to resist the flipped classroom because they learned via lecture, so they suppose their kids should follow the same method. Additionally, many teachers argue that lectures aren't all bad, so why should they take the flipped method(Goodwin \& Miller, 2013). Moreover, some teachers are concerned about the management of the new model. They feel that they will do more work by recording what they could easily do in front of their class.

Another major disadvantage regarding flipping classrooms was that students in some communities might not have access to the internet and might not have technological needs (Gross, 2014). Moreover, Grimsley (2013) pointed out that students' misunderstanding during live lectures required immediate explanation from instructors, therefore, students 
might get confused without answering their questions immediately and this was another considerable disadvantage of the flipped classroom method. In this concern, Moran (2014) also indicated that flipping large class sizes might be difficult for teachers.

Additionally, feedback from participants of Mehring (2014) about the difficulties and benefits regarding learning English in the flipped classroom showed that learning in the flipped classroom was effective since it created a studentcentered environment. It also reported that the flipped classroom developed their communicative English language abilities. On the contrary, the participants described the difficulties regarding learning in the flipped classroom reporting that it could be difficult to participate during the class if students did not come prepared.

\section{PROBLEM OF THE STUDY}

A lot of English language learners have low proficiency in EFL vocabulary classes. Therefore, it is important for teachers to utilize more effective vocabulary teaching methods to improve EFL learners' vocabulary. In this concern, using the flipped classroom method may play an important role in developing Saudi female university students' performance on EFL vocabulary classes.

\section{PURPOSE OF THE STUDY}

The study aimed at:

1. Investigating the effectiveness of using the flipped classroom method in Saudi EFL vocabulary classes.

2. Investigating Saudi female students' perceptions towards using the flipped classroom method in an EFL vocabulary class.

\section{QUESTIONS OF THE STUDY}

To assess the effectiveness of the flipped classroom method in an EFL vocabulary classroom, the researcher investigates two primary questions:

1. Are there any statistically significant differences in the students' vocabulary achievement between the control group (taught traditionally) and the experimental group (taught by using the flipped classroom method) in vocabulary classes that can be attributed to the teaching methods?

2. How are flipped vocabulary classrooms perceived by Saudi female university freshmen students?

\section{LITERATURE REVIEW}

Previous research investigating the use of the flipped classroom model in different subject areas usually showed positive feedback of learners (Gaughan, 2014) and a number of benefits as presented below. Many studies on the application of the flipped classroom model have been conducted with respect to varying academic disciplines in higher education.

Few studies were conducted to examine the effectiveness of the flipped foreign language classroom. Moreover, some studies reported improvements in students' performance and supported flipping classrooms while others reported no improvements in students' achievement. In this concern, Baranovic (2013) revealed some positive results when he investigated the effectiveness of a flipped first-year composition course. The findings of this study also revealed that, students' writing skills improved and benefitted from the flipped classroom method. Grimsley (2013) investigated 19 college students' perceptions toward the flipped method in a writing classroom. Most of the participants liked the video podcasts and preferred the flipped classroom method over the traditional style of lecturing.

More recently, Basal's (2005) study which investigated the perceptions of 47 prospective English teachers towards the flipped language classroom showed that the participants had positive perceptions towards the use of the flipped classroom as an integral part of face-to-face courses. Similarly, Yang (2017) examined the use of a flipped classroom in the English Language subject in secondary classrooms in Hong Kong. The study which involved 57 students from two secondary classes together with two teachers teaching these two classes revealed that the students in general were positive about the flipped classroom.

Additionally, Oki's (2016) mixed-method study investigated students' perceptions towards the impact of the flipped classroom method. Qualitative results indicated that student participants were in favor of the flipped classroom over traditional instruction; however, quantitative data did not reveal statistically significant differences.

From the studies reviewed above, it can be found that there are many benefits of using the flipped classroom pedagogy and students' feedback towards this approach was usually positive. The recent shift from instructor-centered instructional model of learning into student-centered model showed positive results over the learning process. Correspondingly, it was recommended by many researchers that instructors should look for more effective methods that best create more student-centered learning environments. In this concern, few studies were mentioned in this chapter and aimed to investigate the effectiveness of the flipped classroom method of instruction in EFL classes. The positive results of these studies were encouraging to adopt this method and avoid its challenges. To the best of the researcher's knowledge, no study has been conducted in the Saudi context tackling the effectiveness of using the flipped classroom 
method in EFL vocabulary classes unless this studies so far. Therefore, this study was conducted to investigate the efficacy of and Saudi learners' perceptions towards using the flipped classroom method in EFL vocabulary classes.

\section{METHOD}

\section{A. Participants}

The participants of this study were 45 level-one, Saudi female students with an age range between 18-19 enrolled in the intermediate level ENG 120 "Building vocabulary" course at the department of English at Al-Muzahimiah Faculty of Education; Shaqra University. They were divided into two groups; the control group (21 students) and the experimental group (24 students). The participants were randomly chosen from their name list; students with odd numbers joined the control group while students with even numbers joined the experimental group. Prior to this study, the participants had studied English as a subject for at least six years in intermediate and secondary schools before enrolling in the university program.

\section{B. Instruments of the Study}

Two instruments were used in this study to gather the data; a pre-post test and questionnaire. The test was designed in three parts of multiple choice, matching and do as shown between brackets; each question consisted of three items and each item was scored of one mark and the total was out of nine. The questions covered three aspects of vocabulary namely; dictionary practice, word building and miscellaneous.

On the other hand, to determine the participants' perceptions toward using the flipped classroom method in EFL vocabulary classes, students in the experimental group responded to five-point likert-scale questionnaire designed by the researcher after the completion of the experiment. The questionnaire investigated two dimensions; the role of the flipped classroom method in increasing students' enjoyability in EFL vocabulary classes and challenges of using the flipped classroom method in EFL vocabulary classes. To ensure the internal validity of the study, five experts in Applied Linguistics validated the content of the instruments. Furthermore, the reliability of the instruments was piloted and the Cronbach's Alpha reliability coefficient showed that there liability of the test was (0.785).Likewise, the Cronbach's Alpha stability coefficient of the questionnaire was also tested and was found (.763). Both values indicate an acceptable amount of reliability and stability.

\section{Procedure}

Data was collected at the end of the second semester of the academic year 1436-1437 $\mathrm{H}$. The researchers employed pre- and post-test for the control and experimental groups. Building Vocabulary (Eng. 120) was a two-hour, entry-level course offered at Al-Muzahimiah Faculty of Education. The curriculum used and taught in this course was; Elementary Vocabulary by B.J Thomas. This course was basically designed for elementary and intermediate level students with the objective of enabling students to use essential English words effectively.

The participants of this study studied the same syllabus. Both sections began with the traditional style of lecturing until the ninth week of the semester. Starting of week 10, the experimental group began their experience with the flipped classroom method and new lessons were delivered before class time while the control group continued receiving the traditional style of lecturing. At the beginning of the treatment, students in the experimental group had instructions on how to use the snap lectures and an explanation of the purpose of the flipped classroom method was provided as well.

Students in the experimental group were assigned to watch Snap lectures. For each snap, one of the researchers recorded herself introducing words included in some sentences and then explaining their definitions, parts of speech, synonyms and antonyms. Approximately, the snaps were between eight and ten minutes. To encourage students to watch these snaps before class time, the researcher gave students a quiz the other day after watching the lesson from the snaps. These quizzes accounted for $10 \%$ of the students' overall course marks. The quizzes were very short, in the form of multiple choice quizzes. As for the control group, new words were introduced through a Power Point presentation in class. This lecture took approximately 35 minutes per class. The students in this class were assigned some exercises as homework and their role was only taking notes and listening to the lectures.

The control group spent the first 10 minutes reviewing topics from the prior lesson, followed by a vocabulary lecture for 35 minutes. Subsequently, pair tasks and dictionary practices were provided for 35 minutes. Finally, ten minutes were devoted for conclusion. In contrast, the first 10 minutes of the experimental group class time were spent on a quiz covering the previous lesson from the snaps. Since there was no vocabulary lecture for the experimental group, the class spent more time on large group activities, drills, and discussion and dictionary practices for 70 minutes. Finally, ten minutes were devoted for conclusion.

\section{Data Analysis}

Data obtained by the first research question was analyzed using a paired sample t- test using the statistical software SPSS was utilized to analyze the data. Likewise, descriptive statistical analysis was used to analyze the data collected from the questionnaire. The students' responses were shown in means, standard deviations and percentages in order to measure their attitudes toward the role of the flipped classroom method in increasing students' enjoyability in EFL 
vocabulary classes as well as to measure students' perceptions towards the enjoyability and challenges of using the flipped classroom method in EFL vocabulary classes.

\section{RESULTS}

This study was conducted to investigate the effectiveness of using the flipped classroom method in EFL vocabulary classes. Moreover, it also aimed to investigate Saudi female students' perceptions of using the flipped classroom method in EFL vocabulary classes. Subsequently, this chapter reports and discusses the results of the study.

\section{A. First: Students' Academic Performance}

To analyze the results of the first research question, a paired sample t-test was conducted. Table 1 below demonstrates the results of the pre-posttests for the two groups.

TABLE 1

MEAN SCORES OF THE CONTROL AND EXPERIMENTAL GROUPS IN THE PRE-POST TESTS

\begin{tabular}{llll} 
Group & N & Pre-test & Post-test \\
\hline Experimental & 24 & 5.17 & 6.50 \\
\hline Control & 21 & 4.10 & 3.95 \\
\hline
\end{tabular}

Tablelabove shows the mean scores of the control and experimental groups in the pre and post-test.The mean score of the experimental group in the pre-test was (5.17) while the mean score of the post-test was (6.50). On the other hand, the mean score of the control group in the pre-test was (4.10) while the mean score of the post-test was (3.95). As shown in Table 1, the experimental group scored a little higher than the control group did in the pre- test even though both groups had the pre-test together at the same time. Table 2 below shows the results of the paired sample t-test which indicateany potential statistically significant differences between the performances of the two groups.

TABLE 2

\begin{tabular}{|c|c|c|c|c|c|c|}
\hline \multicolumn{7}{|c|}{ PAIRED SAMPLE T-TEST } \\
\hline & Mean & Std. Dev. & Std. Error Mean & $\mathrm{T}$ & Df. & Sig(2-tailed) \\
\hline Pair 1 Pre- Exp post-Exp & -1.333 & 1.373 & .280 & -4.759 & 23 & .000 \\
\hline Pair 2 Pre- Exp post-Exp & .143 & 1.493 & .326 & .439 & 20 & .666 \\
\hline
\end{tabular}

As shown in table 2, the Sig (2-tailed) value for the control group was (.666) and "t" value was (.439) which indicate that there was no statistically significant difference between their performance in the pre-test and post-test. In contrast, the Sig (2-tailed) value for the experimental group was (.000) and " $t$ " value was (- 4.759). Table 2 indicates that there was a statistically significant difference between the two groups' performance in the pre-test and post-test. This difference is in favor of the experimental group since the level of achievement of the experimental group was higher than the control group.

Subsequently, this result supported the findings of Mehring (2014) which suggested that the flipped classroom method was beneficial in improving students language skills since students in the flipped class performed much higher. This result also supported the findings of (Overmyer, 2014; Gaughen, 2014) which revealed that students in the inverted classrooms had score slightly higher than students in the non-inverted classrooms. Moreover, this result also supported the findings of Baranovic (2013) which showed that students' writing skills improved. On the contrary, these findings contradict Moran's findings (2014) which revealed that overall student achievement decreased in the flipped section. The findings of this study also are against the findings of Guy and Marquis (2016) who found that there were no statistically significant differences between the flipped classroom method and the traditional method.

\section{B. Second: Students' Perceptions}

The first section of the questionnaire was concerned with the students' attitudes towards the role of the flipped classroom method in increasing students' enjoyability in EFL vocabulary classes. Table 3 below shows the frequencies, percentages, means and standard deviations of the participants' perceptions toward using the flipped classroom model in increasing their enjoyability of the classroom.

TABLE 3

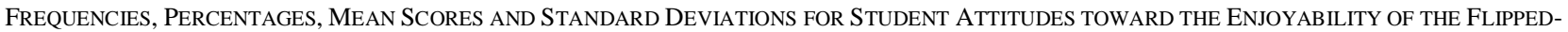
CLASSROOM METHOD IN EFL VOCABULARY CLASSES

\begin{tabular}{|c|c|c|c|c|c|c|c|c|}
\hline Item & & SA & $\mathbf{A}$ & TS & D & SD & Mean & SD \\
\hline \multirow[t]{2}{*}{ 1. I enjoy watching a video for homework. } & $\mathbf{F}$ & 14 & 8 & 2 & - & - & \multirow[t]{2}{*}{4.50} & \multirow[t]{2}{*}{.659} \\
\hline & $\%$ & 58.3 & 33.3 & 8.3 & - & - & & \\
\hline \multirow{2}{*}{$\begin{array}{l}\text { 2. The flipped classroom method keeps me from } \\
\text { getting bored in a vocabulary class. }\end{array}$} & $\mathbf{F}$ & 15 & 7 & 1 & 1 & - & \multirow[t]{2}{*}{4.50} & \multirow[t]{2}{*}{.780} \\
\hline & $\%$ & 62.5 & 29.2 & 4.2 & 4.2 & - & & \\
\hline \multirow{2}{*}{$\begin{array}{l}\text { 3. The flipped classroom method helps me to learn } \\
\text { independently. }\end{array}$} & $\mathbf{F}$ & 15 & 8 & 1 & - & - & \multirow[t]{2}{*}{4.58} & \multirow[t]{2}{*}{.584} \\
\hline & $\%$ & 62.5 & 33.3 & 4.2 & - & - & & \\
\hline \multirow{2}{*}{$\begin{array}{l}4 . \text { I enjoy learning with the flipped classroom } \\
\text { method. }\end{array}$} & $\mathbf{F}$ & 13 & 9 & 2 & - & - & \multirow[t]{2}{*}{4.46} & \multirow[t]{2}{*}{.658} \\
\hline & $\%$ & 54.2 & 37.5 & 8.3 & - & - & & \\
\hline
\end{tabular}


Table 3 shows that the means of the participants' responses on the first section of the questionnaire ranged between (4.46 and 4.58) with standard deviations that ranged between (.584 and 780). As shown in Table 3, the highest mean score was for item number three "The flipped classroom method helps me to learn independently" with a mean of 4.58 and a standard deviation of .584. On the contrary, the least mean score in the first section of the questionnaire as shown in table 3 was for item 4 "I enjoy learning with the flipped classroom method" with a mean score of 4.46 and a standard deviation of .658. Furthermore, the general mean of the first section of the questionnaire (4.51) is relatively very high. This value shows that the majority of the participants strongly agreed on the enjoyability of utilising the flipped classroom method in EFL vocabulary classes.

On the other hand, the second section of the questionnaire was concerned with the students' attitudes towards the difficulties related to using the flipped classroom method in EFL vocabulary classes. Table 4 below shows the frequencies, percentages, mean scores and standard deviations of the participants' perceptions toward using the flipped classroom in vocabulary classes.

TABLE 4

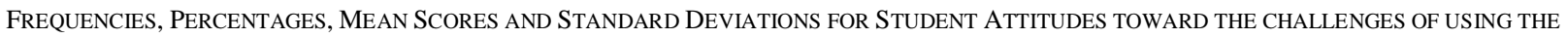
FLIPPED-CLASSROOM METHOD IN EFL VOCABULARY CLASSES

\begin{tabular}{|c|c|c|c|c|c|c|c|c|}
\hline Item & & SA & A & TS & D & SD & Mean & SD \\
\hline \multirow{2}{*}{$\begin{array}{l}\text { 5. I can learn more from a live lecture in the } \\
\text { class than from a video at home }\end{array}$} & $\mathrm{F}$ & 2 & 4 & 7 & 9 & 2 & \multirow[t]{2}{*}{2.79} & \multirow[t]{2}{*}{1.103} \\
\hline & $\%$ & 8.3 & 16.7 & 29.2 & 37.5 & 8.3 & & \\
\hline \multirow{2}{*}{$\begin{array}{l}\text { 6. Learning through the flipped classroom } \\
\text { method makes me more stressed. }\end{array}$} & $\mathrm{F}$ & - & 1 & 3 & 10 & 10 & \multirow[t]{2}{*}{1.79} & \multirow[t]{2}{*}{.833} \\
\hline & $\%$ & - & 4.2 & 12.5 & 41.7 & 41.7 & & \\
\hline \multirow{2}{*}{$\begin{array}{l}\text { 7. It is hard for me to get access to the } \\
\text { internet and watch the assigned videos. }\end{array}$} & $\mathrm{F}$ & 1 & 2 & 5 & 8 & 8 & \multirow[t]{2}{*}{2.17} & \multirow[t]{2}{*}{.584} \\
\hline & $\%$ & 4.2 & 8.3 & 20.8 & 33.3 & 33.3 & & \\
\hline \multirow{2}{*}{$\begin{array}{l}\text { 8. I do not prefer the flipped classroom } \\
\text { method of instruction. }\end{array}$} & $\mathrm{F}$ & - & 2 & 1 & 9 & 12 & \multirow[t]{2}{*}{4.46} & \multirow[t]{2}{*}{.658} \\
\hline & $\%$ & - & 8.3 & 4.2 & 37.5 & 50.0 & & \\
\hline
\end{tabular}

Table 4 shows that the means of the participants' responses on the second section of the questionnaire ranged between (4.46 and 4.58) with standard deviations that ranged between (.584 and 780). the highest mean was 2.79 for item number five as $29.2 \%$ of the students believed that the statement was true sometimes, $8.3 \%$ strongly agreed, $37.5 \%$ disagreed, $8.3 \%$ strongly disagreed that they can learn more from a live lecture in class than from a video at home. The second highest mean score was 2.17 for item number seven, indicating that $29.2 \%$ of the students believed that the statement was true sometimes, $4.2 \%$ strongly agreed, $8.3 \%$ agreed, $33.3 \%$ disagreed, $33.3 \%$ strongly disagreed that it was hard for them to get access to internet to watch the assigned videos.

Moreover, item number six in Table 4 received the mean score (1.79), indicating that $12.5 \%$ of the students believed that the statement was true sometimes, $4.2 \%$ agreed, $41.7 \%$ disagreed, $41.7 \%$ strongly disagreed that learning through the flipped classroom method made them more stressed. The lowest mean score was 4.46 for item number eight of Table 4.4, indicating that $4.2 \%$ of the students believed that the statement was true sometimes, $8.3 \%$ agreed, $37.5 \%$ disagreed, $50.0 \%$ strongly disagreed that they do not prefer the flipped classroom method of instruction.

Subsequently, this result supported the findings of Gross (2014) which proved that the flipped classroom method was enjoyable to students since it enabled them to work collaboratively in class; Grimsley (2013) who reported that the students liked and enjoyed the flipped classroom procedure; Mehring (2014) whose study revealed that the flipped classroom model created a student-centered environment; Oki (2016) whose participants were in favor of the flipped classroom method; both Basal 2005 and Yang (2017) whose participants showed positive perceptions to the flipped classroom method. This finding also supported the findings of Mehring (2014) which revealed that the students' experience in the flipped classroom was positive. Moreover, this result supported the findings of Grimsley (2013) which reported that most of the participants preferred the flipped classroom method over the traditional style of lecturing.

It is worth mentioning that the findings of the current study did not reveal any of the drawbacks of the flipped classroom method shown by previous researchers. The findings of this study did not support Lents and Cifeuentes (2009) and (2012) who criticized the method from different views. The findings also did not show disadvantages like those mentioned by Goodwin and Miller (2013) who claimed that the method adds extra burdens on the shoulders of the teachers. On the other hand, Gross (2014) found that some participants might not have access to the internet which has not been tackled in the current study. Furthermore, the current study did not also show findings like those of Moran (2014) who reported the problem of managing large flipped language classes.

\section{IMPLICATIONS OF THE STUDY}

Findings from this study prove that using the flipped classroom method in an EFL vocabulary class is beneficial; therefore, EFL instructors are advised to use the flipped classroom method in EFL classes. This method can devote class time for practicing language which, in turn, improves students' English language proficiency.EFL instructors may need training programs in order to flip their classes perfectly. On the other hand, EFL learners should be trained on how to watch the assigned educational videos. This encourages them to learn on their own peace effectively 


\section{RECOMMENDATIONS FOR FURTHER RESEARCH}

Currently, the area of the flipped language classroom requires further research on this topic. Therefore, based on the findings of this study, implementing the flipped classroom method may be more effective in applied EFL courses such as grammar, syntax and writing which need more time for practicing more exercises. The participants of this study were students at the university level; it is recommended that a similar study is applied on students at schools as well.

\section{CONCLUSION}

Students' performance in the post-test revealed that there were significant differences which were in favor of the experimental group. This finding suggested the effectiveness of the flipped classroom method in EFL vocabulary classes. Findings of the questionnaire indicated that students' attitudes towards using the flipped classroom method in EFL vocabulary classes were positive. The results of the first dimension of the questionnaire confirmed that the participants strongly enjoyed their experience with the flipped vocabulary class. The results of the second dimension of the questionnaire showed that most of the students believed that using the flipped classroom method was not challenging for them.

There were several limitations of the study which need to be pointed out. First and foremost, without the direct assistance of the instructor, some students with low English language abilities encountered difficulties in understanding some of the snap lectures, specifically, in word building section. Much effort was done to involve weak students in the class and to assist them even outside their class time. Another limitation was the students who had already taken the course and might have advantage over the new students. The researcher excluded the sheets of those students. A final limitation involved the value of the textbook to the participants which seemed to vanish with the videos the students watch. The teacher practices emphasized both the values of the videos and the textbook to overcome this limitation.

To conclude, this study proved that using the flipped classroom method in EFL vocabulary classes was beneficial for Saudi female university students. It could improve students' English language vocabulary proficiency and increased students' enjoyability. Moreover, it made an important contribution to the field of teaching methods. As a result, instructors who were interested in flipping their EFL vocabulary classes were advised to adopt the flipped classroom method of instruction.

\section{REFERENCES}

[1] Basal, A. (2015).The Implementation of a Flipped Classroom in Foreign Language Teaching. Turkish Online Journal of Distance Education 4(16): 28-37

[2] Gaughan, J. (2014). The flipped classroom in world history. The History Teacher, 47(2), 222-244

[3] Goodwin, B. \& Miller, K. (2013). Evidence on flipped classrooms is still coming in. Educational Leadership, 70(6), 78-80

[4] Grimsely, C. (2013). New media and the inverted classroom: investigating their impact on women in first- year composition. Unpublished Doctoral Dissertation. Texas Women's University: Denton.

[5] Gross, A. (2014). The flipped classroom: Shakespeare in the English classroom. Unpublished Doctoral Dissertation. North Dakota State University: Fargo.

[6] Guy, R., \& Marquis, G. (2016). The flipped classroom: A comparison of student performance using instructional videos and podcasts versus the lecture-based model of instruction. Issues in Informing Science and Information Technology, 13, 1-13

[7] Hamdan, N., McKnight, P., McKnight, K., \&Afstrom, K. M. (2013). A review of flipped learning. Retrieved from Flipped Learning Network website: http://www.flippedlearning.org/cms/lib07/VA01923112/Centricity/Domain/41/LitRevi. (accessed 29/5/2016).

[8] Lage, M., Platt, G., \& Treglia, M. (2000). Inverting the classroom: A gateway to creating an inclusive learning environment. Journal of Economic Education, 31(1), 30-43.

[9] Lents, N., Cifuentes, O. (2009). Web-Based Learning Enhancements: Video Lectures through Voice-Over PowerPoint in aMajors-Level Biology Course. Journal of College Science Teaching, 39, 38-46

[10] Mehring, J. (2015). An exploratory study of the lived experiences of Japan undergraduate EFL students in the flipped classroom. Unpublished Doctoral Dissertation. Pepperdine University: Malibu

[11] Moran, C. (2014).Changing paradigms: a mixed methods study of flipping the English language arts classroom. Unpublished Doctoral Dissertation. North Carolina State University: Raleigh

[12] Oki, Y. (2016). Flipping a content-based ESL course: An action research report. Hawaii Pacific University TESOL Working Paper Series 14, 62-75

[13] Overmeyer, G. (2014).The flipped classroom model for college algebra: effects on student achievement. Unpublished Doctoral Dissertation. Colorado State University: Fort Collins

[14] Prefume, Y. (2015).Exploring a flipped classroom approach in a Japanese language classroom: a mixed methods study .Unpublished Doctoral Dissertation. Baylor University: Texas

[15] Song, W. (2014).Application of Flipped Classroom to Vocational College English Teaching. Overseas English, 36.

[16] Strayer, J. (2012). How learning in an inverted classroom influences cooperation, innovation and task orientation. Learning Environments Research, 15(2), 171-193

[17] Tucker, B. (2012). The flipped classroom. Education. Next, 12(1), 82-83

[18] Yang, C. C. R. (2017). An investigation of the use of the 'flipped classroom' pedagogy in secondary English language classrooms. Journal of Information Technology Education: Innovations in Practice, 16, 1-20. 
Sarah Saleh Alnuhayt is an English instructor at Almuzahimiah faculty of education, Shaqra University. She got her master's degree in linguistics from Al-Imam Muhammad bin Saud Islamic University, Riyadh, Saudi Arabia. 